\title{
Socio-economic determinants for alcohol consumption and heavy episodic drinking in a Ugandan student population
}

\author{
Martin Stafström and Anette Agardh \\ Division of Social Medicine and Global Health, Department of Clinical Sciences, Malmö, Lund University, Sweden
}

\section{ABSTRACT}

Aims: To examine whether the socio-economic determinants of alcohol use found in high-income university student settings are also true of Uganda.

Design: Two cross-sectional surveys, conducted in 2005 and 2010, combined into a single dataset.

Setting: Mbarara University of Science and Technology (MUST) in southwestern Uganda

Participants: 2,934 students $(N$ in $2005=980 ; N$ in $2010=1,954)$. Total response rate $=76.8 \%$.

Results: Multivariate logistic regression showed the following socio-economic determinants to be positively associated with alcohol consumption: having attended boarding school (for males only); being Catholic; religion not playing a big role while growing up; head of household having had secondary education or higher (for females only); being a student of development studies, tropical forest conservation or computer science (the latter two for males only). Being Muslim or, for males, being a non-Anglican Protestant were negatively related to alcohol use. Different patterns were found for heavy episodic drinking. Being a male Muslim or a male student of development studies was positively related to heavy episodic drinking; while among females, being of a non-classified faith, having had a head of the household with a secondary education, not being raised by both parents, or being a student of development studies or science were positively related to heavy episodic drinking.

Conclusion: Alcohol consumption and heavy episodic drinking on a monthly basis among the students at MUST seem linked to a student's socio-economic background, with varying patterns for male and female students.

Alcohol use is a grave health concern in Uganda. The World Health Organization (WHO) (2000) found that Uganda, together with Nigeria, had Africa's highest per capita consumption of alcohol. Even though the proportion of abstainers is quite high- $51 \%$ of all males and $61 \%$ of all femalesweekly heavy episodic drinking was found among $33 \%$ of Ugandan males and II\% of Ugandan females.
Although alcohol use is considered to be a crucial public health challenge in Uganda, very little research has investigated the socio-economic determinants of alcohol use. In recent years, the international GENACIS project, funded by the European Union and the U.S. National Institute on Alcohol Abuse and Alcoholism (NIAAA), has compared gender-specific drinking patterns across countries, including Uganda (GENACIS, n.d.; Obot

Correspondence: Martin Stafström, Division of Social Medicine and Global Health, SUS Malmö, 20502 Malmö, Sweden

Phone: +464039142

Fax: +4640391390

E-mail: martin.stafstrom@med.lu.se

Financial support: Sida—the Swedish International Development Co-operation Agency

Keywords: alcohol use, heavy episodic drinking, university students, Uganda 
\& Room, 2005). The project has generated several studies that showed large discrepancies in alcohol use and alcohol-related harm by gender and country (Wilsnack, Wilsnack, Kristjanson, Vogeltanz-Holm, \& Gmel, 2009). Based on the GENACIS data, one Ugandan study investigated the relationship between social networks and alcohol consumption, finding frequency of social interaction associated with levels of alcohol use (Tumweisgye, Kasirye, \& Nansubuga, 2009). The socio-economic characteristics of Uganda, and the problem of alcohol abuse and its determinants, are complex. A larger body of research on socio-economic determinants of different alcohol consumption patterns is needed in order to design broadly based, effective policies and interventions.

One characteristic of alcohol use is that consumption patterns vary over the lifespan (Filmore, I987). A body of research from high-income countries has shown, for example, that university students drink more alcohol than many other groups in a society (Borsari \& Carey, 2006). One explanation for this is that they usually are in the age group (I8 to 25) when alcohol use peaks (Kuntsche, Rehm, $\&$ Gmel, 2004). However, very little is known about age patterns and alcohol use in low-income countries (Karam, Kypri, \& Salamoun, 2007).

Alcohol use does not play a dominant role in Ugandan academic culture, as compared to higher education institutions in Europe, where alcohol is often consumed at official university functions. Students-or even the university itself-run oncampus bars, and alcohol use in dormitories is rarely regulated. In contrast, official university functions in Uganda are alcohol-free and there are no on-campus alcohol sales or alcoholic beverage services. In addition, the university dormitories have a zero tolerance alcohol policy; that is, no alcohol is allowed and consumption may lead to suspension of studies. Nevertheless, Ugandan university students continue to consume alcohol. Since the number of enrolled students is on the rise in Uganda and a greater proportion of Ugandan youth will attend higher education, universities are becoming an excellent arena for preventing alcohol-related harm among young adults, as already is the case in high-income countries (Larimer, Cronce, Lee, \& Kilmer, 2004-2005).

A considerable body of research has studied the relationship between socio-economic determinants and alcohol use in a general population (Bloomfield, Grittner, Kramer, \& Gmel, 2006; Mäkelä, ı999; Marmot, I997; van Oers, Bongers, van de Goor, \& Garretsen, I999), as well as in sub-groups such as university students (Caamono-Isorna, Corral, Parada, \& Cadaveira, 2008; Crawford, I995; Dantzer, Wardle, Fuller, Pampalone, \& Steptoe, 2006). These studies have found cultural background-specifically, faith and religious observance- to be of great importance (Bradby \& Williams, 2006; Dotinga, van den Eijnden, Bosveld, \& Garretsen, 2006). Other socioeconomic determinants related to alcohol use have also been identified, such as education (Droomers, Schrijvers, Stronks, van de Mheen, \& Mackenbach, I999; Hemmingsson, Lundberg, Romelsjö, \& Alfredsson, I997), vocation (Hemmingsson et al., I997; Mandell, Eaton, Anthony, \& Garrison I992), financial capacity (Brinkley, I999; Crawford, I995) and family structure (Hill et al., 20Io; Ledoux, Miller, Choquet, \& Plant, 2002). In addition, research has indicated that the impact of alcohol-related harm increases with poverty (Commission on Social Determinants of Health, 2008). Among university students, stress related to academic performance has been shown to have a significant impact on alcohol use (Andersson, 2009; Ham \& Hope, 2003). However, these findings have all come from settings in high-income countries.

In order to prevent alcohol disorders in Uganda, especially among its university students, the association between socio-economic determinants and alcohol use in this specific setting must be ascertained. The aim of this study is to investigate the hypothesis that the above mentioned socioeconomic determinants of alcohol use identified in high-income university student settings are also true of Uganda.

\section{Method}

\section{Population and setting}

In I989, Mbarara University of Science and Technology (MUST) became the second university in Uganda. The number of universities has since expanded, and by 2010 there were 29 institutions of higher education (5 public and 24 private). As a result, a far greater proportion of Ugandan youth are currently enrolled at universities throughout the country than in the past.

A first-year MUST student will generally live in an on-campus dormitory (known locally as hostels). Such students normally stay on campus for one or two academic years, after which they move to privately run hostels off campus. However, students 
on full government scholarships will stay on campus for the length of their studies. Most university students have attended boarding schools, but for most, this is the first time they live unsupervised.

We analyzed a cross-sectional data sample based on a single questionnaire administered twice, five years apart (2005 and 20I0). In both instances, all currently enrolled undergraduates present in class were surveyed. In 2005, our sample was drawn from the three faculties MUST had at the time: Medicine, Science and Development Studies. There were then I,220 undergraduate students enrolled. In 20Io, MUST had expanded to five faculties through the addition of Computer Sciences and Tropical Forest Conservation. The number of enrolled undergraduates in 2010 had increased to almost 2,600 students.

The data were collected by means of an IIpage self-administered instrument consisting of 132 questions. The questionnaire was based on validated instruments used in other studies and on the outcome of focus group discussions initiated to generate survey questions. The questionnaire was pre-tested by Io students in 2005 .

In both 2005 and 2010, the survey took place in lecture halls, with a member of the research team present. Prior to the distribution, students were orally informed about the purpose of the questionnaire and were given instructions on how to fill it out. Written informed consent was obtained for each participant. In 2005, 980 students responded to the questionnaire (response rate $80 \%$ ) while in 2010, I,954 students completed the survey (response rate $75 \%$ ). The combined sample response rate was, therefore, $76.8 \%$. The Institutional Ethics Review Committee at MUST approved the questionnaire and study design.

\section{Study measures}

In this study, we have applied two outcome variables: alcohol use and heavy episodic drinking (HED) on a monthly basis.

Alcohol use was determined by a graduated quantity/frequency measure (Midanik, I994). Alcohol users were categorized as those students who had consumed alcohol in the last I2 months prior to the survey.

Monthly HED was based on the question "How often do you drink six glasses of wine, beer or whiskey or more on the same occasion?" The five response alternatives were (I) Daily, or almost daily, (2) Every week, (3) Every month, (4) Less than once a month and (5) Never. Those respondents who answered with alternatives I through 3 were categorized as engaging in monthly HED.

We also applied a number of independent variables in the analyses:

Age was applied as a dichotomized variable: those 22 years or under, and those 23 years or over. The cut-off was based on the median age in the sample (22 years).

Faith was based on the question "What was the main religion in the family where you grew up?" Seven alternative answers were provided: (I) Protestant, (2) Catholic, (3) Muslim, (4) Pentecostal, (5) Seventh Day Adventist, (6) Orthodox and (7) Other. Categories 4 and 5 were combined as "Other Protestants," because these two faiths strongly advocate abstinence from alcohol. Categories 6 and 7 were combined into "Other," because Orthodox students were very few in number $(0.8 \%$ in $2005 ; 0.6 \%$ in 20I0).

The variable Religion did not play a big role while growing up was based on the question "What role did religion play in your family when you grew up?" The answer alternatives were (I) Religion played a big role, (2) Religion was relatively important, (3) Religion was not so important, and (4) Religion was not important at all. We then recoded the variable by dichotomizing the students. Those responding with answer alternative I were coded into one category (indicating an upbringing in which religion played an important role) and those responding with alternatives 2 to 4 into the other.

Growing up in an urban area sought to determine whether students grew up in an urban, semi-urban or rural setting. The variable was dichotomized by combining urban and semi-urban into one category.

Head of household had secondary education or higher was based on a closed question about the level of education the head of household had. Those students who answered that the level was equivalent to or higher than a secondary school education were coded into this category.

Whom did you grow up with derived from the question "Which adults did you live with most of the time when you grew up?" The answer alternatives were (I) My mother, (2) My father, (3) My mother and my father, and (4) Other. The answers were dichotomized, with those answering by alternative 3 coded into one category and those responding with the other three alternatives coded into another.

Attended boarding school for 3 or more years was a variable based on the question "Did you go to 
boarding school?" The answer alternatives were (I) Yes, I to 3 years, (2) Yes, more than 3 years, and (3) No, I did not go to boarding school. The answers were dichotomized by coding answer alternative 2 into one category and answer alternatives I and 3 into the other.

\section{Statistical methods}

Chi-square tests and logistic regression modeling were performed using PASW (SPSS) I8. We performed logistic regression bivariate analyses and multivariate analyses to assess adjusted associations between the independent and dependent variables. Confidence intervals were calculated on the $95 \%$ level to estimate statistical significance.

\section{Results}

About $50 \%$ of the male and $35 \%$ of the female students at MUST used alcohol (see Table I). Among them, $34 \%$ of the males and $23 \%$ of the females engaged in HED on a monthly basis. A greater proportion of the male students who used alcohol were in the higher age category, compared to the female students. The variables "religion played a big role while growing up," "growing up in an urban area," "head of household had secondary education or higher" and "attended boarding school for 3 or more years” were all more common among female students.

Table 1

Descriptive results and chi-square test of distribution across men and women of the different dependent and independent variables included in the study

\begin{tabular}{|c|c|c|c|c|c|}
\hline \multirow[t]{2}{*}{ Variable } & \multicolumn{2}{|c|}{ Men } & \multicolumn{2}{|c|}{ Women } & \multirow{2}{*}{$\begin{array}{c}\text { Chi-square } \\
\text { Sig. }\end{array}$} \\
\hline & $\mathbf{N}$ & $\%$ & $\mathbf{N}$ & $\%$ & \\
\hline Consumed alcohol in past 12 months & 806 & 49.6 & 381 & 35.1 & $0.000 * * * *$ \\
\hline $\begin{array}{l}\text { Monthly heavy episodic drinking among } \\
\text { past } 12 \text { month drinkers }\end{array}$ & 262 & 34.1 & 85 & 23.4 & $0.000 * * *$ \\
\hline Age & & & & & $0.000 * * * *$ \\
\hline Up to 22 & 773 & 44.9 & 726 & 59.8 & \\
\hline 23 and older & 902 & 52.4 & 433 & 35.7 & \\
\hline Religious affiliation & & & & & 0.905 \\
\hline Anglican & 766 & 44.5 & 557 & 45.9 & \\
\hline Catholic & 668 & 38.8 & 460 & 37.9 & \\
\hline Other Protestant & 114 & 6.6 & 87 & 7.2 & \\
\hline Muslim & 124 & 7.2 & 81 & 6.7 & \\
\hline Other & 31 & 1.8 & 22 & 1.8 & \\
\hline $\begin{array}{l}\text { Religion did not play a big role while } \\
\text { growing up }\end{array}$ & 987 & 57.4 & 787 & 64.8 & $0.000 * * *$ \\
\hline Grew up in an urban area & 861 & 50.1 & 752 & 61.9 & $0.000 * * * *$ \\
\hline $\begin{array}{l}\text { Head of household had secondary educa- } \\
\text { tion or higher }\end{array}$ & 1,000 & 58.1 & 830 & 68.4 & $0.000 * \cdots * *$ \\
\hline Grew up with: & & & & & $0.042 *$ \\
\hline Both mother and father & 871 & 50.6 & 656 & 54.0 & \\
\hline Single parent or other & 836 & 48.6 & 551 & 45.4 & \\
\hline Attended boarding school & & & & & $0.000 * * * *$ \\
\hline For less than 3 years & 577 & 33.5 & 320 & 26.4 & \\
\hline For 3 years or more & 1,127 & 65.5 & 880 & 72.5 & \\
\hline Faculty affiliation & & & & & $0.000 * * * *$ \\
\hline Medicine & 524 & 30.5 & 308 & 25.4 & \\
\hline Development Studies & 532 & 30.9 & 561 & 46.2 & \\
\hline Science & 482 & 28.0 & 193 & 15.9 & \\
\hline Other & 151 & 8.8 & 128 & 10.5 & \\
\hline
\end{tabular}

$* \mathrm{p}<.05 ; * * \mathrm{p}<.01 ; * * * \mathrm{p}<.001$ 
The distribution of variables was not identical in the samples gathered in 2005 vs. 2010 (see Table 2). The proportion of students engaging in HED on a monthly basis was lower in 20I0. However, the proportion of female students engaging in monthly HED was greater in 20I0. In 2010 the proportion of students coming from homes where religion was important, of those who lived in urban areas, and of those who came from homes where the head of the household had achieved a secondary school degree, was higher than in 2005 .

Table 2

Descriptive results and chi-square test of distribution across the 2005 and 2010 surveys of the different dependent and independent variables included in the study

\begin{tabular}{|c|c|c|c|c|c|}
\hline \multirow[t]{2}{*}{ Variable } & \multicolumn{2}{|c|}{2005} & \multicolumn{2}{|c|}{2010} & \multirow{2}{*}{$\begin{array}{l}\text { Chi-square } \\
\text { sig. }\end{array}$} \\
\hline & $\mathbf{N}$ & $\%$ & $\mathbf{N}$ & $\%$ & \\
\hline Consumed alcohol in past 12 months & 411 & 44.8 & 785 & 43.3 & 0.233 \\
\hline $\begin{array}{l}\text { Monthly heavy episodic drinking among } \\
\text { past } 12 \text { month drinkers }\end{array}$ & 154 & 37.5 & 206 & 26.2 & $0.000^{* * * *}$ \\
\hline Male students & 633 & 64.6 & 1,087 & 55.6 & $0.000 * * * *$ \\
\hline Female students & 347 & 35.4 & 1,060 & 44.4 & $0.000 * * *$ \\
\hline Age & & & & & $0.000 * * * *$ \\
\hline Up to 22 & 459 & 47.1 & 1,043 & 55.5 & \\
\hline 23 and older & 516 & 52.9 & 836 & 44.5 & \\
\hline Religious affiliation & & & & & $0.015 *$ \\
\hline Anglican & 420 & 42.6 & 910 & 46.8 & \\
\hline Catholic & 386 & 39.1 & 752 & 38.7 & \\
\hline Other Protestant & 70 & 7.1 & 134 & 6.9 & \\
\hline Muslim & 86 & 8.7 & 119 & 6.1 & \\
\hline Other & 25 & 2.5 & 30 & 1.5 & \\
\hline $\begin{array}{l}\text { Religion did not play a big role while } \\
\text { growing up }\end{array}$ & 550 & 55.8 & 1,235 & 63.5 & $0.000 * * * *$ \\
\hline Grew up in an urban area & 555 & 56.5 & 1,071 & 55.2 & 0.268 \\
\hline $\begin{array}{l}\text { Head of household had secondary } \\
\text { education or higher }\end{array}$ & 731 & 75.4 & 1,112 & 58.4 & $0.000 * * * *$ \\
\hline Grew up with: & & & & & 0.851 \\
\hline Both mother and father & 510 & 52.0 & 1,023 & 52.4 & \\
\hline Single parent or other & 238 & 48.0 & 476 & 47.6 & \\
\hline Attended boarding school & & & & & 0.130 \\
\hline For less than 3 years & 662 & 67.1 & 1,355 & 69.9 & \\
\hline For 3 years or more & 324 & 32.9 & 584 & 30.1 & \\
\hline Faculty affiliation & & & & & $0.000 * * * *$ \\
\hline Medicine & 367 & 37.7 & 472 & 28.9 & \\
\hline Development Studies & 334 & 34.3 & 768 & 39.9 & \\
\hline Science & 273 & 28.0 & 407 & 21.1 & \\
\hline Other & $\mathrm{n} / \mathrm{a}$ & $\mathrm{n} / \mathrm{a}$ & 280 & 14.5 & \\
\hline
\end{tabular}

$* \mathrm{p}<.05 ; * * \mathrm{p}<.01 ; * * * \mathrm{p}<.001 ; \mathrm{n} / \mathrm{a}=$ not applicable 
In the bivariate logistic regression, where each independent variable was analyzed separately against the two outcome variables, all independent variables-apart from growing up in an urban area, survey year and age-was statistically associated with either alcohol use or having engaged in monthly HED (Table 3).

Table 3

Results of bivariate logistic regression analyses with 95\% confidence intervals (CI) of the association between the independent variables and consuming alcohol in past 12 months and having experienced monthly heavy episodic drinking (HED), for men and women respectively

\begin{tabular}{|c|c|c|c|c|c|c|c|c|}
\hline & \multicolumn{4}{|c|}{ Past 12 month drinkers } & \multicolumn{4}{|c|}{ Monthly HED } \\
\hline & \multicolumn{2}{|c|}{ Men } & \multicolumn{2}{|c|}{ Women } & \multicolumn{2}{|r|}{ Men } & \multicolumn{2}{|c|}{ Women } \\
\hline & OR & $95 \% \mathrm{CI}$ & OR & $95 \% \mathrm{CI}$ & $\mathbf{O}$ & $95 \% \mathrm{CI}$ & $\mathbf{O}$ & $95 \% \mathrm{CI}$ \\
\hline & & & & & $\mathbf{R}$ & & $\mathbf{R}$ & \\
\hline \multicolumn{9}{|l|}{ Religion } \\
\hline Anglican & 1.0 & Ref. & 1.0 & Ref. & 1.0 & Ref. & 1.0 & Ref. \\
\hline Catholic & 1.5 & $1.22-1.87$ & 1.4 & $1.10-1.88$ & 0.7 & $0.52-0.98$ & 0.6 & $0.35-1.06$ \\
\hline Other Protestant & 0.4 & $0.23-0.58$ & 0.8 & $0.44-1.29$ & 1.9 & $0.87-4.19$ & 1.9 & $0.72-4.88$ \\
\hline Muslim & 0.2 & $0.15-0.41$ & 0.3 & $0.17-0.66$ & 4.4 & $1.68-11.71$ & 2.0 & $0.55-7.60$ \\
\hline Other & 1.2 & $0.57-2.46$ & 0.5 & $0.82-4.93$ & 1.4 & $0.50-3.79$ & 7.1 & $1.75-28.92$ \\
\hline $\begin{array}{l}\text { Religion did not play a big role } \\
\text { while growing up }\end{array}$ & 1.4 & $1.14-1.70$ & 1.6 & $1.21-2.02$ & 1.4 & $1.02-1.86$ & 1.3 & $0.78-2.09$ \\
\hline Grew up in an urban area & 1.1 & $0.88-1.29$ & 1.3 & $1.03-1.74$ & 1.2 & $0.92-1.67$ & 0.7 & $0.41-1.13$ \\
\hline $\begin{array}{l}\text { Head of household had secon- } \\
\text { dary education or higher }\end{array}$ & 1.5 & $1.20-1.79$ & 1.8 & $1.35-2.43$ & 1.3 & $0.97-1.83$ & 1.8 & $0.93-3.59$ \\
\hline $\begin{array}{l}\text { Did not grow up with both } \\
\text { mother and father }\end{array}$ & 0.9 & $0.77-1.14$ & 0.9 & $0.73-1.2$ & 0.9 & $0.66-1.92$ & 0.5 & $0.30-0.82$ \\
\hline $\begin{array}{l}\text { Attended boarding school for } 3 \\
\text { years or more }\end{array}$ & 1.6 & $1.32-2.00$ & 1.1 & $0.80-1.41$ & 0.8 & $0.61-1.18$ & 0.7 & $0.42-1.24$ \\
\hline \multicolumn{9}{|l|}{ Faculty affiliation } \\
\hline Medicine & 1.0 & Ref. & 1.0 & Ref. & 1.0 & Ref. & 1.0 & Ref. \\
\hline Development Studies & 1.5 & $1.20-1.97$ & 0.9 & $0.68-1.25$ & 1.8 & $1.21-2.55$ & 2.9 & $1.54-5.64$ \\
\hline Science & 0.8 & $0.65-1.09$ & 0.6 & $0.37-0.83$ & 0.9 & $0.59-1.40$ & 2.7 & $1.12-6.41$ \\
\hline Other & 2.1 & $1.42-3.10$ & 0.8 & $0.52-1.29$ & 1.0 & $0.60-1.80$ & 1.2 & $0.40-3.60$ \\
\hline Survey year 2010 & 1.0 & $0.82-1.23$ & 1.0 & $0.75-1.30$ & 0.8 & $0.56-1.03$ & 0.6 & $0.37-1.04$ \\
\hline 23 years or older & 1.0 & $0.85-1.26$ & 1.1 & $0.85-1.42$ & 1.3 & $0.93-1.72$ & 1.3 & $0.75-2.04$ \\
\hline
\end{tabular}


Table 4

Results of multivariate logistic regression analyses of consuming alcohol in past 12 months and having experienced monthly heavy episodic drinking (HED), and the association with independent variables for men and women respectively

\begin{tabular}{|c|c|c|c|c|c|c|c|c|}
\hline & \multicolumn{4}{|c|}{ Past 12 month drinkers } & \multicolumn{4}{|c|}{ Monthly HED } \\
\hline & \multicolumn{2}{|c|}{ Men } & \multicolumn{2}{|c|}{ Women } & \multicolumn{2}{|c|}{ Men } & \multicolumn{2}{|c|}{ Women } \\
\hline & OR & CI 95\% & OR & CI 95\% & OR & CI 95\% & OR & CI 95\% \\
\hline \multicolumn{9}{|l|}{ Religion } \\
\hline Anglican & 1.0 & Ref. & 1.0 & Ref. & 1.0 & Ref. & 1.0 & Ref. \\
\hline Catholic & 1.8 & $1.40-2.23$ & 1.4 & $1.06-1.90$ & 0.9 & $0.63-1.26$ & 0.6 & $0.29-1.04$ \\
\hline Other Protestant & 0.5 & $0.29-0.78$ & 0.7 & $0.41-1.30$ & 2.0 & $0.84-4.60$ & 1.5 & $0.48-4.76$ \\
\hline Muslim & 0.3 & $0.17-0.49$ & 0.3 & $0.16-0.68$ & 6.7 & $2.28-19.52$ & 1.8 & $0.42-7.70$ \\
\hline Other & 1.1 & $0.50-2.55$ & 1.3 & $0.47-3.41$ & 1.1 & $0.33-3.43$ & 7.1 & $1.28-39.16$ \\
\hline $\begin{array}{l}\text { Religion did not play a big role } \\
\text { while growing up }\end{array}$ & 1.4 & $1.12-1.74$ & 1.6 & $1.18-2.08$ & 1.4 & $0.99-1.93$ & 1.1 & $0.58-1.91$ \\
\hline Grew up in an urban area & 1.0 & $0.79-1.26$ & 1.3 & $0.92-1.70$ & 1.4 & $0.96-1.95$ & 0.7 & $0.35-1.30$ \\
\hline $\begin{array}{l}\text { Head of household had } \\
\text { secondary education or higher }\end{array}$ & 1.5 & $1.19-1.92$ & 1.7 & $1.23-2.40$ & 1.3 & $0.87-1.83$ & 3.0 & $1.30-7.00$ \\
\hline Did not grow up with both & 1.2 & $0.93-1.44$ & 1.1 & $0.86-1.48$ & 1.0 & $0.72-1.39$ & 2.3 & $1.25-4.08$ \\
\hline $\begin{array}{l}\text { mother and father } \\
\text { Attended boarding school for } \\
3 \text { years or more }\end{array}$ & 1.5 & $1.22-1.95$ & 0.9 & $0.69-1.30$ & 1.0 & $0.67-1.41$ & 1.0 & $0.54-2.02$ \\
\hline Faculty affiliation & 1.0 & Ref. & 1.0 & Ref. & 1.0 & Ref. & 1.0 & Ref. \\
\hline Medicine & 1.9 & $1.41-2.47$ & 1.1 & $0.79-1.53$ & 2.1 & $1.40-3.23$ & 3.0 & $1.38-6.74$ \\
\hline Development Studies & 1.1 & $0.80-1.41$ & 0.7 & $0.44-1.05$ & 0.9 & $0.59-1.51$ & 3.7 & $1.39-9.75$ \\
\hline $\begin{array}{l}\text { Sclence } \\
\text { Other }\end{array}$ & 2.1 & $1.37-3.26$ & 1.0 & $0.59-1.62$ & 1.4 & $0.78-2.67$ & 1.3 & $0.39-4.51$ \\
\hline Survey year 2010 & 0.9 & $0.74-1.19$ & 1.2 & $0.84-1.59$ & 0.7 & $0.51-1.06$ & 0.9 & $0.46-1.71$ \\
\hline $\begin{array}{l}\text { Survey year } 2010 \\
\text { Age } 23 \text { years or older }\end{array}$ & 1.1 & $0.90-1.39$ & 1.1 & $0.86-1.51$ & 1.3 & $0.91-1.78$ & 1.3 & $0.69-2.29$ \\
\hline
\end{tabular}

In the multivariate logistic regression (Table 4), the socio-economic determinants that appeared to be statistically significantly associated with alcohol use among male students were being of the Catholic faith, growing up in a family where religion did not play a big role, having a head of household who had graduated from secondary school, having attended a boarding school for at least three years, and being a student of development studies, computer science or science. On the other hand, belonging to a non-Anglican Protestant faith or being a Muslim was negatively associated with alcohol use.

Among the female students, the independent variables significantly associated with alcohol use were being Catholic, growing up in a family where religion did not play a big role, and having a head of household who had graduated from secondary school. In addition, being a Muslim had a negative association with alcohol use.

For monthly HED the pattern was somewhat different. Among the male students using alcohol, being Muslim and being a student in the Faculty of 
Development Studies were both significantly associated with HED. Growing up in an urban setting and being raised in a home where religion was not important both also tended to be associated with monthly HED, although not to a statistically significant degree.

Among the female students, having a faith classified as "Other," having a head of household who had graduated from secondary school, not having grown up with both one's mother and father, and studying in either the Faculty of Development Studies or in the Faculty of Science were all strongly associated with monthly HED. Being Catholic also showed a tendency to be negatively associated with HED, though the association was not statistically significant.

\section{Discussion}

The results showed different patterns for men and women regarding the socio-economic determinants associated with alcohol use and monthly HED. This finding underlines the need to adapt gender-specific alcohol prevention strategies.

Our analyses of Ugandan university students were based mainly on risk factors identified in the research from high-income countries, cited above. Our results indicated that these risk factors are also present among Ugandan students, although there are differences. There may be varying explanations for this. First, alcohol consumption patterns in Uganda do not resemble those of Europe and North America (Kullgren, Alibusa, \& Birabwa-Oketcho, 2009; Wilsnack et al., 2009). Second, socioeconomic status patterns differ considerably between sub-Saharan Africa and high-income countries (Commission on Social Determinants of Health, 2008). Third, alcohol use is largely a cultural phenomenon. Thus, the diverse cultural setting of Uganda, as illustrated by this study, results in variable alcohol use. These factors suggest that in a low-income sub-Saharan country, alternative epidemiological models than those applied in highincome regions are needed to interpret the socioeconomic determinants of alcohol use.

Our study highlights the need to develop those epidemiological models. But to do so successfully, the general alcohol consumption patterns of sub-Saharan Africa, and those of university students in particular, need to be better understood. Other studies have found that Uganda's per capita alcohol consumption is on a par with the European region
(WHO, 2000). However, such findings are not supported by our data, since university populations-at least in affluent societies such as the United States-typically consume more alcohol than the general population (SAMHSA/OAS, 2003). This indicates a two fold epidemiological challenge for sub-Saharan Africa: in order to map the relationship between socio-economic determinants and different health outcomes, more knowledge is needed of how these mechanisms function in that context. Another challenge is to accurately describe the lifestyles, such as patterns of alcohol use, associated with different health outcomes.

Our analyses showed that students from a more affluent and less traditional background-that is, those who were brought up in a relatively secular environment by well-educated parents-were more likely to use alcohol, which matches findings from higher-income settings (Dantzer et al., 2006; Silva, Malbergier, Stempliuk, \& de Andrade, 2006). In this study, however, this background was not, among the men, associated with engaging in monthly HED, as has been the case in studies from high-income settings (Dantzer et al., 2006; Humensky, 20I0). Among the women, the results partially agree with the findings from affluent societies. We suggest that this could be a result of female alcohol use, and in particular heavy use, being less accepted in a traditional Ugandan setting. These findings might logically seem to suggest that Ugandan social policy should counteract economic growth. However, economic growth is one of the leading success factors for improving health in lowand middle-income countries (Skolnik, 2008). Therefore, we would suggest rather that Uganda develop a national alcohol policy with regulations and measures that more effectively respond to the current situation.

Another finding in our study was the large differences in alcohol use and monthly HED between faculties. Why students within some faculties are more prone to drink alcohol is something we could not determine, although we hypothesize that students in the Faculty of Medicine are less likely to abuse alcohol due to their interest in health issues. Thus, one might propose that studying medicine has a protective effect, rather than being a risk factor for using alcohol. However, an alternative interpretation might be that in the Faculty of Medicine it is not socially desirable to use alcohol. This could imply that our results may be affected by under-reporting.

\section{Methodological considerations}


There is a lack of research into the socio-economic conditions in the region, and into the relationship between these conditions, including alcohol use, and different health outcomes. We believe that our survey allowed us to encompass a larger number of socioeconomic perspectives relevant to the Ugandan setting than would have been possible if we had used a European or North American questionnaire. The survey included several items that students in focus group interviews raised as important in this particular case. Thus, the instrument we used was tied to the specific setting. The potential disadvantage of this procedure was that some questions had not previously been validated in a low-income setting.

The study design was cross-sectional, leaving causal directions open, though it appears more plausible that socio-economic determinants influence alcohol use than vice-versa, especially among a relatively young population. According to our calculations of statistical power, the sample size was adequate for the main analyses.

We believe that selection bias was a minor problem in our study because of the relatively high response rate $(76.8 \%)$. It might be argued that there was a risk for dependent misclassification since the groups with strict moral rules, that is, those in which religion played a big role, might have systematically underestimated alcohol use due to the social undesirability of such behavior. In principle, this could have led to an exaggeration of certain associations. However, since the link between faith and alcohol use as compared with monthly HED was inconsistent, we do not believe misclassification could have had a major influence on our results.

The finding that Muslim males were at significant risk of engaging in monthly HED should not be exaggerated. The number of students in this category was very small, making it difficult to assume that so few individuals were representative of the overall Muslim student population in Uganda.

The instrument that measured HED used as its inclusion criteria $6+$ drinks per occasion, for both males and females. Normally it is recommended to use a gender-specific measurement, such as $5^{+}$ drinks for men and $4+$ drinks for women (Wechsler $\&$ Nelson, 200I). This means that odds ratios for monthly HED, which in our analyses were insignificant, might have been significant if lower thresholds had been applied. The main implication of this is that we may have missed defining risk factors that another study design might have identified.

In Uganda, about Io\% of an age cohort continues on to tertiary education, and the children of the most affluent families are clearly the ones most likely to do so. Therefore, we believe that it is difficult to apply the findings of this study to the same age cohorts of the general population of Uganda. Nevertheless, since MUST is a good representative of a university community outside the capital region, we believe the present study is highly representative for this type of setting.

\section{Conclusions}

Alcohol consumption and monthly HED among students in Uganda are associated with socioeconomic background factors, but with different patterns for young men and women. These findings indicate that previous conclusions, from highincome countries, on the association between a more affluent socio-economic background and alcohol use, are also valid in a low-income setting such as Uganda. However, this association was not found among male Ugandan students in relation to monthly HED. This finding has implications for policy formulation as well as for university policies on student conduct. Policy-makers would benefit from involving young people, to better understand how to formulate feasible policy goals that would increase their ability to choose relevant implementation strategies for the target group.

\section{References}

Andersson, C. (2009). Alcohol use and stress in university freshmen: A comparative intervention study of two universities [doctoral thesis]. Lund, Sweden: Lund University.

Bloomfield, K., Grittner, U., Kramer, S., \& Gmel, G. (2006). Social inequalities in alcohol consumption and alcohol-related problems in the study countries of the EU concerted action "Gender, culture and alcohol problems: A multi-national study." Alcohol and Alcoholism, 41(Suppl), I26-I36.

Borsari, B., \& Carey K. (2006). How the quality of peer relationships influences college alcohol use. Drug and Alcohol Review, 25, 36I-370.

Bradby, H., \& Williams, R. (2006). Is religion or culture the key feature in changes in substance use after leaving school? Young Punjabis and a comparison group in Glasgow. Ethnicity and Health, 11, 307-324.

Brinkley, G. L. (I999). The causal relationship be- 
tween socioeconomic factors and alcohol consumption: A Granger-causality time series analysis, I950-I993. Journal of Studies on Alcohol, 60, 759-768.

Caamano-Isorna, F., Corral, M., Parada, M., \& Cadaveira, F. (2008). Factors associated with risky consumption and heavy episodic drinking among Spanish university students. Journal of Studies on Alcohol and Drugs, 69, 308-3I2.

Commission on Social Determinants of Health. (2008). Closing the gap in a generation: Health equity through action on the social determinants of health. Geneva, Switzerland: World Health Organization.

Crawford, C. M. (I995). Alcohol-consumption patterns among undergraduates: The impact of family income. Journal of Alcohol and Drug Education, 40, I-9.

Dantzer, C., Wardle, J., Fuller, R., Pampalone, S. Z., \& Steptoe, A. (2006). International study of heavy drinking: Attitudes and sociodemographic factors in university students. Journal of American College Health, 55, 83-89.

Dotinga, A., van den Eijnden, R. J. J. M., Bosveld, W., \& Garretsen, H. F. L. (2006). Religious, cultural, and social cognitive correlates of alcohol use among Turks and Moroccans in The Netherlands. Addiction Research and Theory, 14, 4I3-43I.

Droomers, M., Schrijvers, C. T. M., Stronks, K., van de Mheen, D., \& Mackenbach, J. P. (I999). Educational differences in excessive alcohol consumption: The role of psychosocial and material stressors. Preventive Medicine, 29, I-IO.

Filmore, K. M. (1987). Women's drinking across the adult life course compared to men. British Journal of Addiction, 82, 80I-8II.

GENACIS. (n.d.). GENACIS-Gender, alcohol, and culture: An international study [Website]. Retrieved from http://genacis.org.

Ham, L. S., \& Hope, D. A. (2003). College students and problematic drinking: A review of the literature. Clinical Psychology Review, 23, 719-759.

Hemmingsson, T., Lundberg, I., Romelsjö, A., \& Alfredsson, L. (I997). Alcoholism in social classes and occupations in Sweden. International Journal of Epidemiology, 26, 584-591.

Hill, K. G., Hawkins, J. D., Bailey, J. A., Catalano, R. F., Abbott, R. D., \& Shapiro, V. B. (2010). Person-environment interaction in the prediction of alcohol abuse and alcohol dependence in adulthood. Drug and Alcohol Dependence, 110, 62-69.

Humensky, J. L. (2010). Are adolescents with high socioeconomic status more likely to engage in alcohol and illicit drug use in early adulthood? Substance Abuse Treatment, Prevention, and Policy, 5, I9. doi:10.1186/1747-597X-5-19

Karam, E., Kypri, K., \& Salamoun, M. (2007). Alcohol use among college students: An international perspective. Current Opinion in Psychiatry, 20, 213-22I.

Kullgren, G., Alibusa, S., \& Birabwa-Oketcho, H. (2009). Problem drinking among patients attending primary healthcare units in Kampala, Uganda. African Journal of Psychiatry, 12, 52-8.

Kuntsche, E., Rehm, J., \& Gmel, G. (2004). Characteristics of binge drinkers in Europe. Social Science Q Medicine, 59, II3-I27.

Larimer, M. E., Cronce, J. M., Lee, C. M., \& Kilmer, J. R. (2004-2005). Brief intervention in college settings. Alcohol Research \& Health, 28, 94-104.

Ledoux, S., Miller, P., Choquet, M., \& Plant, M. (2002). Family structure, parent-child relationships, and alcohol and other drug use among teenagers in France and the United Kingdom. Alcohol and Alcoholism, 37, 52-6o.

Mäkelä, P. (1999). Alcohol-related mortality as a function of socioeconomic status. Addiction, 94, $867-886$.

Mandell, W., Eaton, W. W., Anthony, J. C., \& Garrison, R. (I992). Alcoholism and occupations: A review and analysis of I04 occupations. Alcoholism: Clinical and Experimental Research, 16, 734-746.

Marmot, M. (I997). Inequality, deprivation and alcohol use. Addiction, 92(Suppl), si3-20.

Midanik, L. T. (I994). Comparing usual quantity/frequency and graduated frequency scales to assess yearly alcohol consumption: Results from the I990 United States National Alcohol Survey. Addiction, 89, 407-4I2.

Obot, I., \& Room, R. (Eds.). (2005). Alcohol, gender and drinking problems: Perspectives from low and middle income countries. Geneva, Switzerland: World Health Organization.

SAMHSA/OAS. (2003). Results from the $2002 \mathrm{Na}$ tional Survey on Drug Use and Health: National findings. DHHS Publication (SMA) 03-3836. Washington, D.C., U.S.A.: National Institute of Health.

Silva, L. V. E. R., Malbergier, A., Stempliuk, V. D., \& de Andrade, A. G. (2006). Factors associated with drug and alcohol use among university students. Revista de Saúde Pública, 40, 280-288.

Skolnik, R. L. (2008). Essentials of global health. Sudbury, U.S.A.: Jones \& Bartlett Learning. 
Tumweisgye, N. M., Kasirye, R., \& Nansubuga, E. (2009). Is social interaction associated with alcohol consumption in Uganda? Drug and Alcohol Dependence, 103, 9-15.

van Oers, J. A. M., Bongers, I. M. B., van de Goor, L. A. M., \& Garretsen, H. F. L. (I999). Alcohol consumption, alcohol-related problems, problem drinking, and socioeconomic status. Alcohol and Alcoholism, 34, 78-88.

Wechsler, H., \& Nelson, T. F. (200I). Binge drinking and the American college student: What's five drinks? Psychology of Addictive Behaviors, 15, 287-29I.

Wilsnack, R. W., Wilsnack, S. C., Kristjanson, A. F., Vogeltanz-Holm, N. D., \& Gmel, G. (2009). Gender and alcohol consumption: Patterns from the multinational GENACIS project. Addiction, 104, I587-1600.

World Health Organization. (2000). Global status report on alcohol and health. Geneva, Switzerland: World Health Organization. 